\title{
Canada needs a national strategy for anesthesia services in rural and remote regions
}

\author{
Beverley A. Orser MD PhD, C. Ruth Wilson MD
}

Cite as: CMAJ 2020 July 27;192:E861-3. doi: 10.1503/cmaj.200215

$\mathbf{R}$

ural and remote areas of Canada are at risk of losing surgical and obstetric services because of a shortage of anesthesia care providers. For more than a century, anesthesia, surgical and obstetric services were available in the remote community of Bella Coola, British Columbia. ${ }^{1}$ However, since the health authority cut maternity services at the local hospital in 2008, women from this community have had to travel to Williams Lake (a 6-hour drive) and live there for the last month of their pregnancy. ${ }^{2}$ Many receive almost no assistance for meals and housing or support for their other children. Similarly, in Nova Scotia, a shortage of anesthesiologists means that elective surgeries have been reduced and pregnant women in some communities have had to travel to Halifax for their deliveries. ${ }^{3,4}$

We discuss the causes of these rural shortages of anesthesiology services and propose a national strategy to address the current and future anesthesia needs of rural and remote communities in Canada, organized around 5 central tenets: social accountability, policy interventions, rural and remote practice models, a national research agenda, and mentorship and continuing professional education.

\section{Who delivers anesthesiology services in Canada?}

Currently, 3 groups of physicians provide anesthesia care in the country: Canadian-trained specialist anesthesiologists, internationally trained anesthesiologists and family physician anesthetists. Certified anesthesia assistants contribute in many urban centres, but nurse anesthetists, common in the United States, are not a major feature of anesthesia service provision in Canada.

\section{Why is there a shortage of anesthesia services in rural Canada?}

The current lack of adequate anesthesia services in rural Canada is playing out against a background of a general shortage of physicians in rural areas and chronic shortages of anesthesiologists countrywide.

Canadians living in rural areas comprise $18 \%$ of the population but are served by only $8 \%$ of physicians. ${ }^{5}$ Increased urbanization of medical services has contributed to the attrition of anesthesia, surgical and obstetric care services in rural Canada. ${ }^{5}$ This

\section{KEY POINTS}

- Anesthesia services are essential for the provision of surgical, obstetric and emergency services in rural Canada.

- An overall shortage of anesthesiologists is projected for Canada; thus, investment in health human resource planning and innovative training strategies are required to address this shortage.

- Family physician anesthetists, who bring other generalist skills to rural communities, have been cost-effective care providers in rural Canada for decades.

- A national strategy for the provision of rural anesthesia services includes 5 key components: social accountability, policy interventions, rural and remote practice models, a national research agenda, and mentorship and continuing professional education.

lack of services disproportionally affects remote Indigenous populations, which often have poorer health outcomes than nonIndigenous populations. The mismatch of physicians and population results, in part, from the perception that quality of care improves with volumes of procedures, such that centralized care is safer. Although this is true for complex procedures, low-risk procedures - including low-risk obstetric care - can be performed safely in smaller hospitals. ${ }^{6-8}$ Indeed, delivery of low-risk procedures close to the patient's home is often preferable, to avoid the difficulties and expenses of medical travel in a large country like Canada. Physicians may choose not to work in rural areas because of practice patterns, finances, education and personal factors. ${ }^{9}$

In 2019, the Canadian Anesthesiologists' Society reported the need for more anesthesiologists and predicted a shortfall in services. ${ }^{10}$ Vacancy rates are greatest in smaller hospitals, and facilities with fewer than 5 operating rooms have a proportionally greater number of unfilled positions. ${ }^{11}$ Problems of unfilled advertised positions and urgent requests for locum coverage are widespread.

The specialty anesthesiology workforce comprises about 3300 physicians, more than $13 \%$ of whom are older than 65 years. ${ }^{12}$ Each year, 121 entry positions are available for specialty training in anesthesiology accredited by the Royal College of Physicians and Surgeons of Canada, but more positions are needed. ${ }^{13}$ The overall shortage, including in urban centres, means that fewer anesthesiologists are available to work in rural areas. For the Toronto 
area alone, about 31 and 78 anesthesiologists will be needed in the next 1 and 5 years, respectively, but the city has only 21 first-year training positions (personal experience of one of the authors). Many graduating residents seek out 1 of 205 fellowship positions that are available in Canada to prepare them for academic positions in an urban centre; an orientation to address the needs of rural Canada is not high on the list of motivators for these residents. ${ }^{14}$

Internationally trained specialists have filled some service gaps, but many international physicians struggle to obtain the national certification examination and provincial licensure. Furthermore, most international medical graduates in postgraduate anesthesia training programs are visa trainees. These visa trainees are granted temporary employment as residents and will not remain in Canada. ${ }^{15}$ Of the international students who graduated from any postgraduate program in 2016, only 26 (4.5\%) were practising in rural towns and $39(6.8 \%)$ in small towns 2 years later. ${ }^{16}$ Thus, we cannot rely on international medical graduates to address specialist deficits in rural Canada.

Most rural and remote communities need doctors with broad skill sets to work in emergency departments, obstetrics units and family practice clinics, as well as anesthesia. The physicians who meet these needs are usually family physicians, some of whom also provide anesthetic care. Currently, about 500 family physician anesthetists work in rural Canada, but they are located almost exclusively in Ontario and the western provinces. ${ }^{4}$ The College of Family Physicians of Canada accredits a 1-year training program for family physician anesthetists, using a set of priority topics and key features developed nationally for assessment of competence. After completion of this program, a Certificate of Added Competence in Family Practice Anesthesia may be awarded, which has continuing professional development requirements for maintenance of competence. However, training programs are offered at only 7 of 17 Canadian medical schools, with a total of 22 positions available. Quebec and the Atlantic provinces have no family physician anesthesia programs.

\section{What is the solution?}

A national strategy must be developed and applied to address the pressing human resource shortages in rural anesthesia care. Better workforce planning is needed to inform the development of a national strategy. Canada has been slow to invest in health human resource planning ${ }^{17}$ and the most detailed forecasting for the anesthesia workforce is now 25 years old. ${ }^{11,18,19}$

A national strategy would need to outline the major steps to achieving a sustainable supply of anesthesiologists for rural Canada. One model is the Rural Road Map for Action, developed by the College of Family Physicians of Canada, the Society of Rural Physicians of Canada and others to support an adequate medical workforce for rural Canada., ${ }^{5,20}$ Planning for anesthesia services could build on this model using the following 5 central tenets.

\section{Social accountability}

The social accountability mandate of medical schools and residency programs must be upheld by addressing the needs of rural and Indigenous communities, particularly those communities in their catchment areas. Recruiting physicians for rural practice requires educational strategies such as admitting medical students from rural areas, ensuring meaningful experiences in rural medical education with well-supported rural mentors, and providing training in competencies needed for rural practice. ${ }^{9}$

\section{Policy interventions}

Alignment of medical education with workforce planning will require policies to support the recruitment and retention of physicians in rural areas. Physician remuneration must be adequate but is not sufficient on its own to achieve this goal. Financial support from government for mentorship and coaching programs (as described below) will be helpful, as will additional support for more residency training positions for specialist and family physician anesthetists. Return of service policies may be helpful in recruiting physicians to rural areas, but unless there is a supportive community and practice environment, such initiatives are generally not successful for long-term retention. ${ }^{20}$ National licensing policies are needed that support the deployment of anesthetists to rural areas. Discussions regarding national licensure are currently under way. In fact, during the current coronavirus disease 2019 (COVID-19) pandemic, some jurisdictions have rapidly enabled medical licensure of out-of-province or territory physicians, to expedite locum emergency coverage. ${ }^{21}$ These licensing measures need to be streamlined and expanded across the country to meet the urgent needs of rural communities.22

\section{Rural and remote practice models}

To provide rural and Indigenous communities with timely access to quality health care that meets their needs, physicians in rural areas require a supportive medical environment, support from the rural communities themselves and opportunities for employment for spouses. In the case of anesthesia, a model such as that used in Yellowknife - where a cadre of family physician anesthetists is supported by a regular rota of specialty trained anesthesiologists who provide mentoring and support for difficult cases - would work well.

\section{National research agenda}

A national research agenda that supports rural workforce planning is needed, with the goal of improving access to patientcentred and quality-focused care. Less than $1 \%$ of Canadian Institutes of Health Research funding has been awarded to rural research studies. ${ }^{23}$ Creating this research agenda will require partnership among health care professionals, government policy-makers, communities and academic centres.

\section{Mentorship and continuing professional education}

Professional associations and academic health science centres must develop mentorship and continuing medical education supports for rural anesthetists. ${ }^{24}$ The Clinical Coaching for Excellence program in British Columbia ${ }^{25}$ and a program in Australia are good examples. ${ }^{26}$ The Australian program includes a 2-week paid clinical rotation, which allows general practice anesthetists to work in a regional centre and refresh skills while being assessed by a specialist anesthesiologist. The program facilitates longer-term peer support, and specialist mentorship. ${ }^{27}$ 


\section{Conclusion}

The good news is that Canada's medical schools and professional organizations have started working together to address the shortages. The Collaborative Advisory Group for General and Family Practice Anesthesia is one such initiative. ${ }^{28}$ Provincial, territorial and federal governments must also play an active role in developing the proposed national workforce strategy. Only through such collaboration will Canadians living in rural and remote regions gain reliable access to the anesthetic and pain management care they deserve. Although we have focused here on the current shortage of anesthesia services, the solutions will be best formulated within the framework that also addresses shortages of obstetricians and general surgeons, as well as family physicians providing extended obstetric and surgical services.

The creation of a national strategy for anesthesia services would be a major step toward ensuring that no pregnant mothers are forced to travel hundreds of kilometres from regional and rural health centres that no longer provide robust maternal care programs.

\section{References}

1. Iglesias A, Iglesias S, Arnold D. Birth in Bella Bella: emergence and demise of a rural family medicine birthing service. Can Fam Physician 2010;56:e233-40.

2. Ryan D. Travel for childbirth "terrifying and traumatic" for Bella Coola mom. Vancouver Sun 2019 Sept. 17.

3. Vibert J. Yarmouth hospital crippled by exodus of anesthesiologists. The Chronicle Herald [Halifax] 2019 Apr. 10 [updated].

4. Gorman M. Disagreements lead to N.S. docs missing out on anesthesiology training. CBC [Nova Scotia] 2019 Sept. 12. Available: www.cbc.ca/news/canada/nova -scotia/health-care-doctors-family-practice-anaesthetists-surgery-1.5279835 (accessed 2020 July 8).

5. Rural road map for action: directions. Mississauga (ON): College of Family Physicians of Canada; 2017.

6. Iglesias S Kornelsen J, Woollard R, et al. Joint position paper on rural surgery and operative delivery. Can J Rural Med 2015;20:129-38.

7. Webb RJ, Kantor GSA. Obstetrical epidural anaesthesia in a rural Canadian hospital. Can J Anaesth 1992;39:390-3.

8. Orser B. Obstetrical epidural anaesthesia in a Canadian outpost hospital. Can J Anaesth 1988;35:503-6.

9. Rourke J. Increasing the number of rural physicians. CMAJ 2008;178:322-5.

10. Shortage of anesthesiologists impacts delivery of surgical, acute and chronic pain services: more residency training positions needed [news release]. Toronto: Canadian Anesthesiologists' Society; 2019 May 23. Available: www.newswire.ca/ news-releases/shortage-of-anesthesiologists-impacts-delivery-of-surgical-acute -and-chronic-pain-services-872753250.html (accessed 2020 July 8).

11. Engen DA, Morewood GH, Ghazar NJ, et al. A demand-based assessment of the Canadian anesthesia workforce - 2002 through 2007. Can J Anaesth 2005;52:18-25.
12. Anesthesiology profile. Ottawa: Canadian Medical Association; 2018. Available: www.cma.ca/sites/default/files/2019-01/anesthesiology-e.pdf (accessed 2020 July 8$)$.

13. 2018-2019 specialty report. Ottawa: Canadian Post MD Education Registry; 2019. Available: https://caper.ca/sites/default/files/pdf/specialty/2018-19 _Individual_Specialty_Tables.pdf (accessed 2020 July 8).

14. Khan J, Gilbert J, Sharma A, et al. Perspectives of anesthesia residents training in Canada on fellowship training, research, and future practice location. Can J Anesth 2015;62:956-63.

15. Fact sheet: visa trainees in Canadian postgraduate medical training. Ottawa: Canadian Post MD Education Registry; 2015. Available: https://caper.ca/sites/ default/files/pdf/fact-sheets/FactSheet_Visa_trainees_in_Canadian_PG_medical _training_en.pdf (accessed 2020 July 8).

16. The National IMG Database report. Ottawa: Canadian Post MD Education Registry; 2019.

17. Bourgeault I, Simkin S, Chamberland-Rowe C. Poor health workforce planning is costly, risky and inequitable. CMAJ 2019;191:E1147-8.

18. Ryten E. A physician workforce planning model for the specialty of anesthesia: theoretical and practical considerations. Toronto: Canadian Anesthesiologists' Society; 1995. Available: www.cas.ca/CASAssets/Documents/Affiliates/93 _Ryten-Report.pdf (accessed 2020 July 8).

19. Yang H, Byrick R, Donen N. Analysis of anesthesia physician resources: projected Ontario deficit in 2005. Can J Anesth 2000;47:179-84.

20. Soles TL, Wilson CR, Oandasan IF. Family medicine education in rural communities as a health service intervention supporting recruitment and retention of physicians: advancing rural family medicine: the Canadian Collaborative Taskforce. Can Fam Physician 2017;63:32-8.

21. Frequently asked questions for physicians interested in locum opportunities in the Northwest Territories. Practice NWT; 2019. Available: www.practicenwt.ca/ sites/practicenwt/files/resources/locum_physician_faqs.pdf (accessed 2020 July 8).

22. Ho B, Tepper J, Hinds R. Is it time to implement one national license for Canadian doctors? Healthy Debate; 2020 Mar. 18. Available: https://healthydebate. ca/2020/03/topic/is-it-time-to-implement-one-national-license-for-canadian -doctors (accessed 2020 July 8).

23. Rourke J, Wilson R. Research funding by the Canadian Institutes of Health Research: More rural needed! Can J Rural Med 2020;25:11-13.

24. Angle $\mathrm{P}$, Kurtz Landy $\mathrm{C}$, Murthy $\mathrm{Y}$, et al. Key issues and barriers to obstetrical anesthesia care in Ontario community hospitals with fewer than 2000 deliveries annually Can J Anaesth 2009;56:667-77.

25. Clinical coaching for excellence-rural surgical and obstetrical networks. Vancouver: University of British Columbia; 2020. Available: https://ubccpd.ca/rson-coaching (accessed 2020 July 8).

26. Orser BA, Wilson CR, Rotstein AJ, et al. Improving access to safe anesthetic care in rural and remote communities in affluent countries. Anesth Analg 2019;129:294-300.

27. Continuing professional development standard handbook: 2017-2019. Australia: Joint Consultative Committee on Anesthesia; 2019. Available: www.racgp.org.au /FSDEDEV/media/documents/RACGP/Committees/CCA-CPD-Standard-Handbook .pdf (accessed 2020 July 8).

28. Collaborative Advisory Group for General \& Family Practice Anesthesia. Mississauga (ON): College of Family Physicians of Canada; 2020. Available: https://www.cfpc.ca/ en/member-services/section-of-communities-of-practice-in-familymedic/ collaborative-advisory-group-for-general-and-famil (accessed 2020 July 8).
Competing interests: Beverley Orser reports that she is the named inventor on 2 patents (Canadian Patent 2,852,978 and United States Patent 9,517,265). A third patent is pending (United States Patent: 62/268,137). The 2 issued and 1 pending patents are held by the University of Toronto. The discoveries related to the patents resulted from research performed at the University of Toronto. They identify materials to enhance cognition or so-called "smart drugs". To date, there has been no commercialization of the inventions, including no royalies and no licensing to companies. C. Ruth Wilson reports that she was an employee of Queen's University until June 2018. As Co-Chair of the Rural Road Map implementation committee of the College of Family Physicians of Canada, Dr. Wilson received remuneration for costs of travel to meetings.
This article has been peer reviewed.

Affiliations: Department of Anesthesiology and Pain Medicine (Orser), University of Toronto; Department of Anesthesia (Orser), Sunnybrook Health Sciences Centre, Toronto, Ont.; Department of Family Medicine (Wilson), Queen's University, Kingston, Ont.

Contributors: Both authors contributed to the conception and design of the work, drafted the manuscript, revised it critically for important intellectual content, gave final approval of the version to be published and agreed to be accountable for all aspects of the work.

Correspondence to: C. Ruth Wilson, ruth.wilson@dfm.queensu.ca 